\title{
Sentido y alcance del incidente de impacto fiscal en Colombia*
}

\section{Alejandro Gaviria Cardona*}

Resumen. Debido al alto número de condenas en contra de las entidades públicas, el Congreso de Colombia, mediante el Acto Legislativo o3 de 20 I I, estableció que los efectos de las sentencias judiciales podrán ser modulados, modificados o diferidos siempre que afecten la sostenibilidad fiscal de la entidad condenada. El presente escrito analiza el sentido y alcance del incidente de impacto fiscal, así como sus implicaciones para el debido proceso, la cosa juzgada y la tutela judicial efectiva.

Palabras clave: incidente de impacto fiscal, debido proceso, cosa juzgada, tutela judicial efectiva.

\section{Sense and Purview of the Colombian Tax Impact Incident}

Aвsтract. Due to the high number of convictions against public entities, the Congress of Colombia, through Legislative Act 03 of 201 I, established that the effects of judicial decisions may be modulated, modified or deferred, as long as

Fecha de recepción: 23 de febrero de 20I8. Fecha de aceptación: I4 de mayo de 2018.

Para citar el artículo: Gaviria Cardona, A., "Sentido y alcance del incidente de impacto fiscal en Colombia", Revista de Derecho Privado, Universidad Externado de Colombia, n. ${ }^{\circ} 35$, juliodiciembre de 2018, 391-407. DoI: https://doi.org/IO.I 860I/OI234366.n35.I 5

* Magíster en Derecho Procesal de la Universidad de Medellín. Candidato a doctor en Derecho Privado de la Universidad de Salamanca, España. Docente de Responsabilidad Civil y Contratos en la Universidad Autónoma Latinoamericana y en EAfit, Medellín, Colombia. Abogado litigante. Miembro activo del Instituto Colombiano de Responsabilidad y del Estado (IARCE). Contacto: alejandro.gaviriac@hotmail.com 
they affect the fiscal sustainability of the Condemned entity. In the following paper, the meaning and scope of the fiscal impact incident will be analyzed, as well as its implications for due process, res judicata and effective judicial protection.

Keywords: Incident of fiscal impact, Due Process, res judicata, effective judicial protection.

Sumario. I. Incidente de impacto fiscal. II. La sentencia. III. Firmeza de la sentencia: cosa juzgada. IV. ¿Qué implicaciones tiene modular, modificar o diferir los efectos de la sentencia? V. Corte Interamericana de Derechos Humanos. Conclusiones. Referencias.

\section{Incidente de impacto fiscal}

El Congreso de la República de Colombia, mediante el Acto Legislativo o3 de 20 I I, modificó el artículo 334 de la Constitución Política ${ }^{\mathrm{I}}$ y creó la figura del incidente de impacto fiscal (en adelante, IIF), con del cual se busca que los efectos de las sentencias judiciales condenatorias de las entidades públicas sean modulados, modificados o diferidos para, de esta forma, garantizar la sostenibilidad fiscal de la entidad condenada.

I "Artículo r. ${ }^{\circ} \mathrm{El}$ artículo 334 de la Constitución Política quedará así:

"La dirección general de la economía estará a cargo del Estado. Este intervendrá, por mandato de la ley, en la explotación de los recursos naturales, en el uso del suelo, en la producción, distribución, utilización y consumo de los bienes, y en los servicios públicos y privados, para racionalizar la economía con el fin de conseguir en el plano nacional y territorial, en un marco de sostenibilidad fiscal, el mejoramiento de la calidad de vida de los habitantes, la distribución equitativa de las oportunidades y los beneficios del desarrollo y la preservación de un ambiente sano. Dicho marco de sostenibilidad fiscal deberá fungir como instrumento para alcanzar de manera progresiva los objetivos del Estado Social de Derecho. En cualquier caso el gasto público social será prioritario.

"El Estado, de manera especial, intervendrá para dar pleno empleo a los recursos humanos y asegurar, de manera progresiva, que todas las personas, en particular las de menores ingresos, tengan acceso efectivo al conjunto de los bienes y servicios básicos. También para promover la productividad y competitividad y el desarrollo armónico de las regiones.

"La sostenibilidad fiscal debe orientar a las Ramas y Órganos del Poder Público, dentro de sus competencias, en un marco de colaboración armónica.

"El Procurador General de la Nación o uno de los Ministros del Gobierno, una vez proferida la sentencia por cualquiera de las máximas corporaciones judiciales, podrán solicitar la apertura de un Incidente de Impacto Fiscal, cuyo trámite será obligatorio. Se oirán las explicaciones de los proponentes sobre las consecuencias de la sentencia en las finanzas públicas, así como el plan concreto para su cumplimiento y se decidirá si procede modular, modificar o diferir los efectos de la misma, con el objeto de evitar alteraciones serias de la sostenibilidad fiscal. En ningún caso se afectará el núcleo esencial de los derechos fundamentales.

"Parágrafo. Al interpretar el presente artículo, bajo ninguna circunstancia, autoridad alguna de naturaleza administrativa, legislativa o judicial, podrá invocar la sostenibilidad fiscal para menoscabar los derechos fundamentales, restringir su alcance o negar su protección efectiva". 
Este incidente fue regulado con posterioridad, por medio de la Ley i695 de 2013.

Mediante el IIf se permite que, a petición del Procurador General de la Nación o de alguno de los ministros del despacho, se modifiquen, modulen o difieran los efectos de una sentencia condenatoria proferida por una alta corte, siempre que se afecte de forma seria la sostenibilidad fiscal de la entidad condenada, entendiendo por esta, en materia estatal, aquella que busca que el manejo de los recursos del Estado sea sostenible, o que al menos no produzca déficit, implementando para ello una política financiera responsable y que atienda a los imprevistos propios de su ejercicio financiero.

Precisamente, mediante el IIf se busca que las finanzas de las entidades estatales no se vean seriamente afectadas por el cumplimiento de sentencias jurisdiccionales proferidas en su contra.

\section{La sentencia}

La sentencia ha sido definida como un "acto procesal que pone fin al proceso jurisdiccional, por medio de la obtención de un juicio lógico y un acto de voluntad de un órgano jurisdiccional, en el que se aplican de forma 'creativa' normas integrantes al [sic] sistema de fuentes para un caso concreto [...] Todos los actos procesales antecedentes encuentran su sentido desde este acto final por el que se 'dice el derecho' y permite la solución definitiva de la cuestión controvertida" ${ }^{2}$.

La sentencia, entonces, es el acto procesal que soluciona el conflicto, el cual fue llevado al proceso jurisdiccional por medio de la pretensión procesal y la excepción de mérito.

La sentencia está conformada por tres partes: los antecedentes, que contienen un recuento de lo que se está debatiendo ${ }^{3}$; las consideraciones, que son las explicaciones o las razones que llevan al juez a adoptar esta o aquella decisión; y la decisión, en donde, de forma clara y concisa, se resuelve el conflicto ${ }^{4}$.

En consecuencia, debe el juez explicar las razones de hecho, de derecho y probatorias que lo llevaron a adoptar su decisión, lo cual significa que su decisión debe estar debidamente fundamentada y no puede ser arbitraria.

Se tiene entonces que la sentencia "da vida a un reglamento sustancial de la relación controvertida"5, "reglamento" que comprende, además de la decisión del derecho, la forma en que este debe ser cumplido.

2 Agudelo Ramírez, M., El proceso jurisdiccional, 2. a ed., Medellín, Comlibros, 2006, 389.

3 Este apartado solo procede en los eventos en los cuales la sentencia es escrita, de conformidad con lo establecido en el último inciso del artículo 280 del Código General del Proceso.

4 Agudelo Ramírez, ob. cit., 408.

5 Quintero, B. y Prieto, E., Teoría general del derecho procesal, 4. a ed., Bogotá, Temis, $2008,582$. 


\section{Firmeza de la sentencia: cosa juzgada}

Una vez se pone fin al proceso jurisdiccional con la sentencia, el conflicto intersubjetivo de intereses se extingue, y se les prohíbe a los sujetos procesales volver sobre el asunto, lo cual se conoce como cosa juzgada.

Ahora, la decisión adoptada por el juez no solo debe ser firme (inmutabilidad o inmodificabilidad), sino que debe ser cumplida a cabalidad (efectividad) ${ }^{6}$.

No basta entonces con que la sentencia sea inmodificable sino que la orden jurisdiccional debe verificarse por lo sujetos procesales; luego, "Se tiene derecho fundamental a que se dé eficacia a la sentencia de fondo o mérito" que es la solución concreta al conflicto de intereses que llevó a la activación del aparato jurisdiccional.

La sentencia comprende una decisión que le pone fin al litigio, mediante "un acto jurídico sustancial concreto, una norma concreta que reglamenta la situación que antes era controvertida. Es un nuevo derecho que nace como resultado del ejercicio de la jurisdicción [...] El caso juzgado entra en el sistema jurídico como una nueva regla de derecho sustancial, aunque por consiguiente concreta" $"$.

Esta "nueva regla de derecho sustancial" es la que debe ser cumplida por aquellas personas que intervinieron en el proceso jurisdiccional, sin que se permita volver sobre el asunto, lo cual contribuye a la seguridad jurídica9 ${ }^{9}$.

Pese a esto, la Corte Constitucional colombiana ha entendido que una cosa es la decisión y otra la orden que indica cómo debe cumplirse la decisión, señalando que "si bien ambas hacen tránsito a cosa juzgada, la orden puede ser objeto de variaciones accidentales siempre que se cumplan requisitos que apuntan a asegurar el cumplimiento de lo decidido en la sentencia y el goce efectivo del derecho tutelado" "o, lo cual se conoce como modulación de la sentencia.

\section{IV. ¿Qué implicaciones tiene modular, modificar o diferir los efectos de la sentencia?}

Tal y como se ha anotado, para proferir la sentencia, el juez debe analizar las razones de hecho, de derecho y probatorias que le permitirán adoptar una u otra decisión; pero, mediante el incidente de impacto fiscal se busca que por diversas razones, ajenas al debate inicial, relacionadas única y exclusivamente con

6 Ibíd., 587 .

7 Ibíd., І з 1 .

8 Ibíd., I43.

9 López Blanco, ob. cit., 632.

Io Sentencia T-o86 de 2003, M.P.: Manuel José Cepeda Espinosa. 
la sostenibilidad fiscal, los efectos de la sentencia sean modificados, diferidos o modulados.

Definamos cada una de las expresiones, de acuerdo a la Real Academia de la Lengua Española:

Modificar: I. tr. Transformar o cambiar algo mudando alguna de sus características. U. t. c. prnl. [... ${ }^{\mathrm{II}}$.

Diferir: I. tr. Aplazar (retrasar) $[\ldots]^{\mathrm{I} 2}$.

Modular: [...] 2. tr. Modificar los factores que intervienen en un proceso para obtener distintos resultados $[\ldots]^{13}$.

Nótese que estas definiciones tienen algo en común, y es que todas implican algún tipo de cambio, bien sea en las cualidades, características o en el plazo de ejecución.

Debe advertirse que la Corte Constitucional colombiana trata de diferenciar entre la sentencia y sus efectos, toda vez que entiende que, en ciertos eventos, la sentencia requiere de pronunciamientos posteriores en aras de garantizar su efectividad ${ }^{14}$, por lo cual en diversos pronunciamientos ${ }^{15}$ ha precisado que mediante el IIf no se vulnera la cosa juzgada, toda vez que se limita a la modificación, modulación y diferimiento de los efectos de la sentencia.

En otras palabras, entiende la Corte Constitucional que mediante el incidente de impacto fiscal se modifican, difieren o modulan los efectos de la sentencia y no la sentencia misma; es decir, el IIF no se adelanta frente a la decisión jurisdiccional sino frente a la forma en que la decisión debe ser cumplida ${ }^{16}$.

Debe precisarse que no existe ningún criterio sólido que permita realizar la diferenciación que pretende hacer la corporación: es que los efectos de la sentencia tienen una relación directa con su contenido. Finalmente, lo que se debe cumplir, y la forma de cumplirse, está íntimamente relacionado con la decisión; diferente es que, para garantizar su efectividad, el juez puede proferir decisiones posteriores, pero todas buscando el cumplimiento de la misma, sin que se vulnere, ahí sí, la cosa juzgada.

I I http://dle.rae.es/?id=PUctmue, consultado el i 6 de julio de 20 I 7.

I 2 http://dle.rae.es/?id=DjmZfpP, consultado el I6 de julio de 20 I 7.

I 3 http://dle.rae.es/?id=PVMrsk6IPVSyHsw, consultado el I6 de julio de 20 I 7 .

I4 Sentencia C-288 de 20 I 2, M.P.: Luis Ernesto Vargas Silva.

I 5 Cfr. sentencias C-288 de 2012, M.P.: Luis Ernesto Vargas Silva; C-I052 de 201 2, M.P.: Jorge Ignacio Pretelt Chaljub, y C-870 de 2014, M.P.: Luis Guillermo Guerrero Pérez.

i6 Sentencia C-I052 de 20 2, M.P.: Jorge Ignacio Pretelt Chaljub. 
Luego, carece de fundamento la diferenciación entre la sentencia y sus efectos. Los efectos de la sentencia, realmente, tienen relación con la forma en que la decisión y la "orden de protección”, en términos de la Corte Constitucional, debe ser cumplida. La parte resolutiva de la sentencia, además de comprender la decisión sobre el conflicto, consagra la forma de solucionarse, lo cual, a todas luces, integra una parte de la sentencia, que al modularse comporta, claramente, un desconocimiento a la cosa juzgada.

Ahora, al ejecutarse la providencia se pueden encontrar situaciones en donde el cumplimiento de la misma se haya dificultado por múltiples razones, como por ejemplo el cambio de nombre de la entidad condenada, eventos en los cuales se justifica plenamente la modulación de la sentencia.

Se itera, solo cuando la decisión posterior a la sentencia busque la efectividad o cumplimiento de la providencia será procedente su modulación.

Así lo ha entendido la Corte Constitucional colombiana con relación a la tutela: siempre que se trate de situaciones accidentales y que se busque garantizar la efectividad, el juez de tutela conserva su competencia para proferir decisiones posteriores a la sentencia para garantizar el cumplimiento de su decisión; análisis que hizo extensivo al $\operatorname{IIF}^{17}$.

Dos situaciones deben resaltarse: en primer lugar, nótese que en sede de tutela se permite la modificación de la sentencia ${ }^{18}$, pero siempre en aras de garantizar el cumplimiento y efectividad de la misma, y solo en aspectos accidentales; en segundo lugar, recuérdese que el amparo, también llamado acción de tutela, por diversas razones, cuenta con regulación procesal propia, la cual, en algunos eventos, raya con la informalidad, todo en aras de proteger los derechos fundamentales afectados que buscan ser protegidos mediante esta.

La situación particular o concreta de la tutela no puede hacerse extensiva a otra clase de procedimiento porque se generarían afectaciones al debido proceso, por ejemplo, mediante el desconocimiento de la cosa juzgada. Recuérdese que "lo decidido en la sentencia no puede ser modificado ni siquiera por el mismo juez que la profirió; o sea, la sentencia es inmutable" I9; en otras palabras, "[1] a estabilidad es el atributo propio de lo que se llama cosa juzgada y se ha asociado a la inmodificabilidad de la norma jurisdiccional, una vez adquiera firmeza procesal, evitando que se profieran decisiones contradictorias en sede de nuevos procedimientos" 20 .

Si se permitiera modular, diferir o modificar los efectos de la sentencia, con fines distintos a garantizar su efectividad, se estaría vulnerando la cosa juzgada. 
La sentencia, desde su estructura, se vislumbra como un acto procesal complejo, y es de la sentencia, como acto procesal, que se predica la cosa juzgada ${ }^{2}$.

Pese a lo anterior, la Corte Constitucional colombiana ha señalado que se pueden modificar aspectos accidentales de la sentencia, siempre que sea para garantizar su efectividad. En aras de garantizar el cumplimiento de las finalidades del Estado social de derecho, se permite que, en algunos eventos, el juez pueda modular los efectos de las sentencias que profiere, lo cual debe buscar, única y exclusivamente, la efectividad de su decisión, toda vez que, en ocasiones, la decisión judicial es compleja y requiere de actuaciones adicionales del sujeto, lo que amerita que, para perseguir su cabal cumplimiento, se profieran decisiones adicionales, siempre y cuando estas estén encaminadas a dicha finalidad ${ }^{22}$.

Las razones de sostenibilidad fiscal no son suficientes para modificar, diferir o modular los efectos de la sentencia, toda vez que "no cualquier dificultad para cumplir una obligación implica que esta deba ser tenida por imposible. Así por ejemplo, la desidia administrativa, la falta de dinero o las trabas burocráticas, por sí mismas, no pueden ser invocadas como razones de la imposibilidad para cumplir una orden" 23.

Además, debe tenerse en cuenta que el IIf no busca la modulación de la sentencia en aras de garantizar su cumplimiento o efectividad, sino todo lo contrario: pretende que, por motivos de sostenibilidad fiscal, la sentencia sea modificada, modulada o diferida, pero siempre en beneficio de la entidad estatal condenada.

$¿$ Es que acaso diferir, por ejemplo, los efectos de una sentencia en el tiempo no es una nueva afectación al derecho? No solo se trata de reparar monetariamente, sino que dicha reparación debe ser efectiva, y la efectividad implica celeridad. Finalmente, para modificar los efectos de la sentencia se debe modificar el contenido de la decisión.

Y, efectivamente, así lo ha entendido el Consejo de Estado colombiano, que al resolver un $\operatorname{IIF}^{24}$ consideró que mediante este, indirectamente, se estaba "reconsiderando" lo resuelto, pese a lo cual accedió a diferir los efectos de la sentencia analizada.

2 I Rico Puerta, L. A., Teoría general del proceso, 2. ${ }^{a}$ ed., Bogotá, Leyer, 2008, 806. En ese mismo sentido, cfr. Azula Camacho, J., Manual de derecho procesal, t. i, io. a ed., Bogotá, Temis, 2010,377 .

22 Sentencia T-o86 de 2003, M.P.: Manuel José Cepeda Espinosa.

23 Ibíd.

24 Consejo de Estado, Sala Plena de lo Contencioso Administrativo. Sentencia del 25 de noviembre de 20I4, rad. IJ 25000-23-26-000-I999-00002-05. 
De esta manera, se puede formular una regla procesal al interior del nuevo incidente: la decisión sólo puede afectar el cumplimiento de la sentencia, no la decisión misma; sobre la cual se configura la cosa juzgada.

No obstante la regla indicada, la Sala no desconoce la afectación relativa que sufrirá la cosa juzgada, porque si bien la premisa de entendimiento de este proceso es la descrita en el párrafo anterior, también es cierto que la Constitución admite, a partir de ahora, que el mismo juez que profirió la sentencia la tome para ponderar de nuevo un aspecto suyo: el impacto fiscal que producirá sobre las finanzas públicas. Por ello si bien no es posible cambiar la decisión, por lo menos en lo que se refiere al sentido -condenatorio o absolutorio de forma parcial- habrá que decidir ahora si "procede modular, modificar o diferir los efectos", lo que en el fondo envuelve una reconsideración de lo resuelto, no en cuanto al sentido allí indicado, sino en cuanto a la manera de cumplirlo.

\section{$[\ldots]$}

Sin embargo, para no engañarse incautamente, se sabe que es imposible no alterar la decisión inicial, aunque sea de forma parcial y levemente, cuando la Alta Corte accede a modular, modificar o diferir los efectos de la providencia, pues si se condenó y ordenó cumplir de una manera, decir luego que se cumplirá de otra o en un tiempo diferente al que señaló la sentencia supone, necesariamente, una variación de la orden impartida. En realidad, después de dictarse sentencia, su modulación, modificación o diferimiento, así sea sólo de los efectos de la condena, necesariamente cambia ese aspecto de la misma ${ }^{25}$.

Precisamente esto es lo que se ha venido sosteniendo a lo largo de este escrito: por medio del IIf se desconoce la cosa juzgada, la cual comprende no solo el reconocimiento del derecho, sino también la forma de cumplirlo, así como la tutela judicial efectiva.

La misma Corte Constitucional, con relación a la tutela judicial efectiva, ha expuesto que esta no solo hace parte del derecho de acción, entendido como el derecho de las personas de acudir a la jurisdicción, sin importar si tienen o no la razón -es decir, siendo intrascendente si existe o no alguna norma de derecho sustancial que ampare o legitime su reclamación-, sino que comprende, además, el derecho al cumplimiento o efectividad de la decisión proferida por el órgano jurisdiccional ${ }^{26}$.

En aras de garantizar el cumplimiento de los fines estatales, las decisiones judiciales deben ser plena y cabalmente cumplidas, para así garantizarles a las per- 
sonas la tutela judicial efectiva ${ }^{27}$. Y es que la Corte Constitucional ha sido clara en cuanto a la finalidad que se busca con la modulación de las sentencias, la cual no puede ser otra que garantizar el cumplimiento o efectividad de las mismas ${ }^{28}$.

La Corte Constitucional, al analizar la constitucionalidad del IIF, acogió los argumentos que ha utilizado desde la sentencia T-o86 de $2003^{[29]}$-en donde se exponen las razones que en ejercicio de la acción de tutela permiten al juez, de manera excepcional, continuar con la competencia para proferir diversas decisiones-, pero señaló que, al tenor del artículo 27 del Decreto 259I de I99I, deben encaminarse a asegurar el cumplimiento y efectividad de la sentencia judicial: "El juez de tutela debe garantizar el goce efectivo del derecho, y en aquellos casos en que impartir una orden no basta, es necesario que el juez mantenga el control de la ejecución de la misma" ${ }^{\circ}$.

$\mathrm{El}$ argumento de la Corte Constitucional con relación al IIF, a todas luces, es falaz, en cuanto modular, diferir o modificar los efectos de la sentencia es lo mismo que modular, diferir o modificar el contenido de la misma, máxime cuando a través de este lo que se busca no es garantizar la efectividad de la decisión sino la sostenibilidad fiscal de la entidad condenada.

En cuanto a su aplicación, ya en diversas ocasiones, las altas cortes han tramitado el IIf del que se viene hablando.

Así, la Corte Constitucional, mediante el auto 233 de $2016^{[31]}$, decidió diferir los efectos de la sentencia C-492 de 2015, en donde había declarado la exequibilidad condicionada del artículo ro de la Ley 1607 de 2012, en el entendido de que aplicarla de la forma inicialmente ordenada afectaría gravemente las finanzas de la Nación, toda vez que la privaría del ingreso de, aproximadamente, $\$ 335.000$ millones.

Siendo la sentencia del 5 de agosto de 20 I $_{5}$, en la parte resolutiva se señaló que empezaría a aplicarse "a partir del año gravable siguiente a aquel en que se expide este fallo", es decir, el año gravable 20I6, por lo que mediante el IIF se logró que la Corte difiriera los efectos de su decisión, bajo el entendido de que la sentencia se aplicaría para el periodo gravable 2017.

27 Cfr. sentencias C-337 de 20ı6, M.P.: Jorge Iván Palacio Palacio; C-o86 de 20ı6, M.P.: Jorge Iván Palacio Palacio; T-550 de 20 I6, M.P.: Aquiles Arrieta Gómez; C-1 80 de 2014, M.P.: Alberto Rojas Ríos; T-247 de 2007, M.P.: Rodrigo Escobar Gil; C-454 de 2006, M.P.: Jaime Córdoba Triviño; C-228 de 2002, MM.PP.: Manuel José Cepeda Espinosa y Eduardo Montealegre Lynett; C- 50 de 20 r6, M.P.: Luis Ernesto Vargas Silva.

28 Sentencia T-o86 de 2003, M.P.: Manuel José Cepeda Espinosa.

29 M.P.: Manuel José Cepeda Espinosa.

30 Sentencia T-o86 de 2003, M.P.: Manuel José Cepeda Espinosa.

3 I M.P.: Luis Guillermo Guerrero Pérez. 
De otro lado, en el Consejo de Estado también se ha dado trámite a un IIF, mediante el cual se difirieron los efectos de una sentencia condenatoria en contra del Distrito Capital, con ocasión del relleno sanitario de Doña Juana32.

En este fallo, la Sección Tercera del Consejo de Estado condenó a la entidad demandada a pagar, en favor de las víctimas, la suma de \$2 27.440.5 I I,400 dentro de los ro días siguientes a la ejecutoria.

Por esta razón, el Distrito Capital, a través del Procurador General de la Nación, solicitó dar inicio al incidente de impacto fiscal, el cual fue decidido por la Sala Plena del Consejo de Estado, y en donde se decidió modular la sentencia. Atendiendo que el incidente fue resuelto el 25 de noviembre de 2014 , se ordenó pagar la suma referida en dos cuotas iguales, la primera antes del 3 I de diciembre de 2014 y la otra antes del 3 I de enero de 2015 . Frente a esto, si bien no parece un plazo extenso, debe tenerse en cuenta que entre el momento en el cual se profirió la sentencia condenatoria y el momento de decidir el incidente de impacto fiscal ya habían transcurrido aproximadamente dos años.

Nótese que en ambos eventos el incidente de impacto fiscal fue utilizado de la misma forma: difiriendo en el tiempo el cumplimiento de la sentencia.

Se insiste, "la protección del derecho a un recurso judicial efectivo no puede tener un carácter eminentemente formal, sino que debe ser material. En ese orden de ideas, se estaría ante un modelo de justicia insuficiente en términos de garantía de este derecho, cuando se ha previsto un procedimiento judicial, pero el mismo no permite conferir a los ciudadanos una solución oportuna frente a la exigibilidad de sus derechos" 33 .

El IIF es un mecanismo que atenta contra la efectividad de los derechos de las personas, pues por medio de este se somete a los "justiciables" a una dilación en la efectividad de sus derechos, vulnerándose el derecho a la tutela judicial efectiva -uno de cuyos aspectos clave es la celeridad en el cumplimiento de la sentencia- así como su efectividad: "quienes son titulares de órdenes judiciales, acuerdos conciliatorios o derechos laborales, tienen un derecho fundamental, derivado de los artículos 29 y 229 de la Constitución Política, a que las decisiones que les benefician o sus derechos causados sean efectivamente cumplidos, ya que de lo contrario tales títulos jurídicos devendrían en meras aspiraciones retóricas carentes de realización práctica" 34.

El patrimonio del responsable (o la falta de este) no puede ser un factor determinante para diluir la efectividad del fallo. La sostenibilidad fiscal no es una razón para modificar, diferir o modular los efectos de una sentencia judicial. bre de 2014, rad. IJ 25000-23-26-000-I999-00002-05.

33 Sentencia C-I 59 de 2016 , M.P.: Luis Ernesto Vargas Silva.

34 Sentencia C-oo6 de 20 I 2, M.P.: María Victoria Calle Correa. 
Si se quiere proteger las finanzas públicas no se debe afectar, por segunda ocasión, al ciudadano, sino que se debe atacar el problema de base. Si se quiere evitar que las finanzas públicas se "desangren", se debe partir de una adecuada capacitación y formación a los funcionarios públicos, para que actúen de forma adecuada y regular, evitando así al máximo sentencias condenatorias en contra de las entidades estatales.

Es decir, siendo que las condenas en contra de las entidades estatales se presentan por el actuar de sus funcionarios, exceptuando algunos títulos de imputación especiales que superan el tema de este escrito, lo recomendable es la capacitación de los servidores públicos para de este modo atacar el problema en su origen y no en sus efectos, toda vez que los títulos excepcionales se convierten en simples paliativos ${ }^{35}$.

Es oportuno llamar la atención sobre un aspecto curioso: la Corte Constitucional, en la sentencia C- 370 de $2006^{[36]}$, al estudiar la constitucionalidad del artículo 55 de la Ley 975 de 2005 (llamada Ley de Justicia y Paz), la cual consagraba límites al derecho a la reparación derivados de aspectos presupuestales, consideró que la capacidad económica del responsable era indiferente tanto para fijar el monto indemnizatorio como para determinar la forma de la reparación.

Pero, tratándose de reparaciones a cargo del Estado, la situación fue analizada de forma diferente: para las reparaciones a cargo de responsables diferentes a las entidades estatales es intrascendente la incapacidad presupuestal, pero para la responsabilidad del Estado la misma sí debe ser tenida en cuenta. El mensaje es claro: ¡que reparen los demás, el Estado no!

\section{Corte Interamericana de Derechos Humanos}

Según el Reglamento de la Corte Interamericana de Derechos Humanos (CIDH), esta conserva la facultad de hacerle seguimiento al cumplimiento de sus sentencias, pidiendo informes no solo a los Estados condenados sino también a las víctimas demandantes, y pudiendo además adoptar medidas y proferir decisiones adicionales, pero siempre encaminadas al cumplimiento de la sentencia.

Este tipo de providencias son encabezadas por la CiDH así: "En el ejercicio de su función jurisdiccional de supervisar el cumplimiento de sus decisiones, la Corte ha venido supervisando la ejecución de la Sentencia emitida en el presente

35 Peláez Gutiérrez, J. C., "Los límites constitucionales de la intervención legislativa en el derecho de la responsabilidad extracontractual del Estado: ¡una cuestión bastante compleja!”, en Henao, J. C. y Ospina Garzón, A. F. (coord.), La responsabilidad extracontractual del Estado: ¿qué? ¿por qué? ¿ ¿hasta dónde?, Bogotá, Universidad Externado de Colombia, 20 I 5, 82 3-824.

36 MM.PP.: Manuel José Cepeda Espinosa, Jaime Córdoba Triviño, Rodrigo Escobar Gil, Marco Gerardo Monroy Cabra, Álvaro Tafur Galvis y Clara Inés Vargas Hernández. 
caso en..." 37, para lo cual se fundamenta en "los artículos 33, 62.1, 62.3 y 65 de la Convención Americana y 30 de su Estatuto y se encuentra regulada en el artículo 69 de su Reglamento"38.

$\mathrm{Al}$ igual que ocurre en Colombia en sede de tutela, la CIDH puede modular o modificar su decisión, pero siempre buscando la efectividad de la misma, nunca justificando un incumplimiento de la misma.

Esta facultad se ha establecido de cara a la efectividad del derecho, toda vez que una sentencia que no se cumple o ejecuta, es simplemente letra muerta. Frente a esta situación, la Corte Constitucional colombiana ha dicho que "[l]a Corte Interamericana de Derechos Humanos, en ejercicio de su función consultiva, ha previsto sobre el particular que el derecho a un recurso judicial no solo debe preverse en la legislación de manera formal, sino que también debe contar con las condiciones materiales para que sea "efectivo"'39.

Debe recordarse que la Convención Interamericana de Derechos Humanos se ha estatuido como un límite para la efectiva protección de los derechos humanos, razón por la cual "marcan altos imperativos para el Estado colombiano en materia de responsabilidad internacional, lo cual se constituye, sin lugar a dudas, en límites a la intervención legislativa en cuanto a la responsabilidad extracontractual del Estado"40.

$\mathrm{Al}$ revisar las estadísticas de la CIDH se encuentra que actualmente en 24 procesos se está pendientes de que se emita sentencia ${ }^{4 \mathrm{I}}$, hay 28 sentencias archivadas por cumplimiento ${ }^{42}$ y I 90 se hallan en estado de supervisión ${ }^{43}$, de los cuales a

37 Corte Interamericana de Derechos Humanos. Resolución del 25 de mayo de 2017. Caso Masacres de Río Negro vs. Guatemala. Supervisión de Cumplimiento de Sentencia, disponible en: http://www.corteidh.or.cr/docs/supervisiones/rionegro_25_05_I 7.pdf [consultada el 29 de julio de 2017 ]. En ese mismo sentido encabezó la Corte la Resolución del ro de febrero de 2017. Caso Rodríguez Vera y otros (Desaparecidos del Palacio de Justicia) vs. Colombia. Supervisión de Cumplimiento de Sentencia, disponible en: http://www.corteidh.or.cr/docs/supervisiones/ rodriguez_IO_O2_I7.pdf [consultada el 29 de julio de 2017].

$3^{8}$ Corte Interamericana de Derechos Humanos. Resolución del 25 de mayo de 2017 . Caso Masacres de Río Negro vs. Guatemala. Supervisión de Cumplimiento de Sentencia, cit.

39 Sentencia C-I 59 de 20I6, M.P.: Luis Ernesto Vargas Silva.

40 Peláez Gutiérrez, ob. cit., 835.

4I http://www.corteidh.or.cr/index.php/es/casos-en-tramite-pendientes-de-emitirse-sentencia [consultada el 23 de febrero de 20I8].

42 http://www.corteidh.or.cr/cf/jurisprudenciaz/casos_en_etapa_de_supervision_archivados_ cumplimiento.cfm?lang=es [consultada el 23 de febrero de 20I8].

43 http://www.corteidh.or.cr/cf/jurisprudenciaz/casos_en_etapa_de_supervision.cfm?lang=es [consultada el 23 de febrero de 2018 ]. 
I 5 se les ha aplicado el artículo 65 de la Convención Americana de Derechos Humanos 44 y la situación constatada no ha variado 45 .

Precisamente, en los asuntos en estado de supervisión, la CiDH ha realizado diversos pronunciamientos, encaminados todos a garantizar la efectividad de su sentencia y el cumplimiento de la misma.

Recuérdese que la finalidad del IIF es otra, a saber, la de diferir, modular o modificar los efectos de la decisión en aras de asegurar o proteger la sostenibilidad fiscal de la entidad condenada; no la de hacer efectiva la sentencia.

Por lo anterior, y debido a que la Corte Constitucional no ha declarado la inexequibilidad del IIf, se trae a colación la siguiente observación con referencia al Sistema Interamericano de Derechos Humanos:

Es en extremo preocupante observar que en los últimos años se viene abriendo camino en Colombia una tendencia peligrosa. Frente al gravísimo problema presupuestal que generan los numerosos asuntos litigiosos decididos en contra del Estado colombiano y los actualmente en curso, en algunos sectores se piensa que las reformas normativas regresivas en materia de protección de derechos humanos, de responsabilidad patrimonial del Estado, de acceso a la administración de justicia y de reparación integral son una acertada estrategia de defensa jurídica pública. Esto nos parece equivocado. Por una parte, esta estrategia es errónea y contraria a derecho. Nos llevaría a escenarios oscuros, propios de aquellas épocas, afortunadamente ya superadas, cuando el dogma era la irresponsabilidad patrimonial del Estado, hoy no compatibles con la Constitución y el bloque de constitucionalidad. El precio que se ha de pagar en materia de derechos humanos sería altísimo. Por otra parte, dicha estrategia sería ineficaz en la medida en que dichas reformas muy seguramente serían declaradas inexequibles por la Corte Constitucional. Incluso, de no ser así, estaríamos simplemente trasladando dichos asuntos litigiosos a un escenario internacional, principalmente al Sistema Interamericano de Derechos Humanos, lo cual agravaría aún más el problema presupuestal para el Estado colombiano, dados los altos niveles de exigencia de ese sistema en materia de responsabilidad internacional y de reparación integral para los Estados miembro[s]. Recuérdese además que la Corte Interamericana de Derechos Humanos podrá seguir declarando la responsabilidad del Estado colombiano, sin que importe su regulación interna ${ }^{4}{ }^{6}$.

Reza el artículo referenciado: "La Corte someterá a la consideración de la Asamblea General de la Organización en cada período ordinario de sesiones un informe sobre su labor en el año anterior. De manera especial y con las recomendaciones pertinentes, señalará los casos en que un Estado no haya dado cumplimiento a sus fallos".

45 http://www.corteidh.or.cr/cf/jurisprudencia2/casos_en_etapa_de_supervision.cfm [consultada el 23 de febrero de 20r8].

46 Peláez Gutiérrez, ob. cit., 84I-842. 


\section{Conclusiones}

Mediante el Acto Legislativo 03 de 20 I s se crea el IIF, que permite modular, modificar o diferir los efectos de las sentencias condenatorias en contra de las entidades públicas, por razones de sostenibilidad fiscal; entendiendo por esta, la búsqueda de que los recursos estatales sean sostenibles, o que al menos no produzcan déficit en razón de una política financiera que sea responsable y atienda a los imprevistos propios de su ejercicio financiero; es decir, mediante el IIF se busca que las finanzas de las entidades estatales no se vean seriamente afectadas por el cumplimiento de sentencias jurisdiccionales proferidas en su contra.

La sentencia es el acto procesal que soluciona el conflicto intersubjetivo de intereses. Antes de adoptar su decisión, el juez debe explicar las razones de hecho, de derecho y probatorias que lo llevan a esta, lo cual significa que la sentencia debe estar debidamente fundamentada, sin que con posterioridad sea posible volver a debatir sobre el mismo asunto.

La sentencia no solo debe ser firme, a tal punto que no pueda volver a ser discutida (inmutabilidad o inmodificabilidad de la sentencia), sino que debe ser cumplida a cabalidad (efectividad de la sentencia).

Tanto la modificación como la modulación y el diferimiento de la decisión tienen en común que implican algún tipo de cambio, bien sea en las cualidades, en las características o en el plazo de ejecución.

La Corte Constitucional ha precisado que mediante el IIF no se vulnera la cosa juzgada, toda vez que se limita a la modificación, modulación y diferimiento de los efectos de la sentencia, y no a la sentencia misma, precisando, además, que bajo ningún supuesto se podrán afectar los derechos fundamentales.

No existe ningún criterio sólido que permita realizar la diferenciación que pretende hacer la alta corporación: es que los efectos de la sentencia tienen una relación directa con su contenido. Finalmente lo que se debe cumplir, y la forma de cumplirse, se relaciona íntimamente con la decisión.

En ciertos eventos, la sentencia requiere de pronunciamientos posteriores en aras de garantizar su efectividad, puesto que las órdenes judiciales son complejas, atendiendo que en ocasiones se requieren diversas actuaciones para poder cumplir la sentencia.

Y si bien es cierto que en las decisiones de tutela se consagra la facultad expresa del juez de proferir decisiones posteriores a la sentencia, estas deben estar encaminadas a garantizar la efectividad o el cumplimiento de la misma. Es decir, no existe razón alguna para hacer extensivos al IIF los argumentos que permiten que en la tutela el juez conserve su competencia hasta que cese la vulneración de los derechos fundamentales amparados, toda vez que la única razón del IIF es garantizar la sostenibilidad fiscal de la entidad condenada, lo cual nada tiene que ver con la efectividad de la decisión. 
La situación particular o concreta de la tutela no puede hacerse extensiva a otra clase de procedimiento porque se afectaría el debido proceso, por ejemplo, mediante el desconocimiento de la cosa juzgada y la afectación a la tutela judicial efectiva.

Es que mediante el incidente de impacto fiscal se está sometiendo a los "justiciables" a una dilación en la efectividad de su derecho, con vulneración del derecho a la tutela judicial efectiva, uno de cuyos aspectos clave es la celeridad en el cumplimiento de la sentencia, así como su efectividad.

El patrimonio del responsable (o la falta de este) no puede ser un factor determinante para diluir la efectividad de la misma. La sostenibilidad fiscal no debe ser una razón para modificar, diferir o modular los efectos de una sentencia judicial.

Si se quieren proteger las finanzas públicas no se debe afectar, por segunda ocasión, al ciudadano, sino que se debe atacar el problema de base, que reside en los funcionarios públicos, quienes en últimas son los que llevan a que el Estado no solo sea demandado sino además condenado.

La ciDH también conserva la facultad de hacerle seguimiento al cumplimiento de sus sentencias, pidiendo informes no solo a los Estados condenados sino también a las víctimas demandantes, y además puede adoptar medidas y proferir decisiones adicionales, si bien todas encaminadas al cumplimiento de la sentencia.

$\mathrm{Al}$ igual que ocurre en Colombia en sede de tutela, la CIDH puede modular o modificar su decisión, pero siempre buscando la efectividad de la misma, nunca justificando un incumplimiento de esta, ni buscando diferir, modular o modificar las órdenes impartidas.

La Corte Constitucional, al analizar la constitucionalidad del IIF, reiteró los argumentos que ha utilizado desde la sentencia T-o86 de 2003, en donde se exponen las razones que, en ejercicio de la acción de tutela, permiten al juez, de manera excepcional, continuar con la competencia para proferir diversas decisiones. Y esto no obstante que, al tenor del artículo 27 del Decreto 259I de I99I, deben encaminarse a asegurar el cumplimiento y efectividad de la sentencia judicial, tal y como ocurre en la cidH.

La finalidad del IIf, en cambio, es otra: diferir, modular o modificar los efectos de la decisión en aras de asegurar o proteger la sostenibilidad fiscal, en lugar de buscar hacer efectiva la sentencia.

Permitir que las sentencias sean moduladas, modificadas o diferidas por razones diferentes a garantizar su efectividad genera en el sujeto procesal una afectación a la cosa juzgada, al debido proceso y a la tutela judicial efectiva, lo cual hará que los ciudadanos, en aras de garantizar los derechos humanos, evalúen la oportunidad de acudir a instancias internacionales, tales como la cIDH. 


\section{Referencias}

Agudelo Ramírez, M., El proceso jurisdiccional, Medellín, Comlibros, 2006.

Azula Camacho, J., Manual de derecho procesal, t. I, Teoría general del proceso, ıo. a ed., Bogotá, Temis, 20 Io.

López Blanco, H. F., Procedimiento civil, vol. I, ro. a ed., Bogotá, Dupré, 2009.

Peláez Gutiérrez, J. C., "Los límites constitucionales de la intervención legislativa en el derecho de la responsabilidad extracontractual del Estado: ¡una cuestión bastante compleja!", en Henao, J. C. y Ospina Garzón, A. F., La responsabilidad extracontractual del Estado: ¿qué? ¿por qué? ¿ hasta dónde?, Bogotá, Universidad Externado de Colombia, $2015,799-842$.

Quintero, B. y Prieto, E. Teoría general del derecho procesal, 4. ${ }^{a}$ ed., Bogotá, Temis, 2008.

Real Academia de la Lengua Española. Diccionario de la Lengua Española.

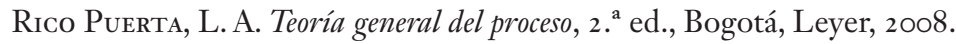

\section{Normatividad}

Acto Legislativo 003 de 201 I.

Constitución Política de Colombia.

Ley 1695 de 2013.

\section{Jurisprudencia}

Consejo de Estado, Sala Plena de lo Contencioso Administrativo. Sentencia del 25 de noviembre de 20I4, rad. IJ 25000-23-26-000-I999-00002-05.

Corte Constitucional. Auto 233 de 20r6, M.P.: Luis Guillermo Guerrero Pérez.

Corte Constitucional. Sentencia C-oo6 de 20 1 2, M.P.: María Victoria Calle Correa.

Corte Constitucional. Sentencia C-086 de 20 16, M.P.: Jorge Iván Palacio Palacio.

Corte Constitucional. Sentencia C-I 59 de 2016, M.P.: Luis Ernesto Vargas Silva.

Corte Constitucional. Sentencia C-I80 de 20I4, M.P.: Alberto Rojas Ríos.

Corte Constitucional. Sentencia C-228 de 2002, MM.PP.: Manuel José Cepeda Espinosa y Eduardo Montealegre Lynett.

Corte Constitucional. Sentencia C-288 de 201 2, M.P.: Luis Ernesto Vargas Silva.

Corte Constitucional. Sentencia C-337 de 20 16, M.P.: Jorge Iván Palacio Palacio.

Sentencia C-370 de 2006, MM.PP.: Manuel José Cepeda Espinosa, Jaime Córdoba Triviño, Rodrigo Escobar Gil, Marco Gerardo Monroy Cabra, Álvaro Tafur Galvis y Clara Inés Vargas Hernández.

Corte Constitucional. Sentencia C- 426 de 2002, M.P.: Rodrigo Escobar Gil.

Corte Constitucional. Sentencia C-454 de 2006, M.P.: Jaime Córdoba Triviño.

Corte Constitucional. Sentencia C-870 de 20I4, M.P.: Luis Guillermo Guerrero Pérez. 
Corte Constitucional. Sentencia C-1052 de 2012, M.P.: Jorge Ignacio Pretelt Chaljub.

Corte Constitucional. Sentencia T-o86 de 2003, M.P.: Manuel José Cepeda Espinosa.

Corte Constitucional. Sentencia T-247 de 2007, M.P.: Rodrigo Escobar Gil.

Corte Constitucional. Sentencia T-550 de 2016, M.P.: Aquiles Arrieta Gómez.

Corte Interamericana de Derechos Humanos. Resolución del io de febrero de 2017. Caso Rodríguez Vera y otros (Desaparecidos del Palacio de Justicia) vs. Colombia Supervisión de cumplimiento de sentencia.

Corte Interamericana de Derechos Humanos. Resolución del 25 de mayo de 201 7. Caso Masacres de Río Negro vs. Guatemala. Supervisión de cumplimiento de sentencia. 